\title{
HIV and the Ramifications for Food Security and Child Health in Affected Communities
}

\author{
Noel W. Solomons ${ }^{\mathrm{a}} \quad$ Gwen Ellen O'Donnell ${ }^{\mathrm{b}}$ \\ ${ }^{a}$ Center for Studies of Sensory Impairment, Aging and Metabolism, Guatemala City, Guatemala, and \\ bProject Concern International, Washington, D.C., USA
}

\section{Key Words}

Human immunodeficiency virus · Acquired

immunodeficiency syndrome $\cdot$ Food insecurity $\cdot$ Food

security $\cdot$ Developing countries $\cdot$ Agriculture $\cdot$ Food aid $\cdot$

Opportunistic infections $\cdot$ Poverty

\begin{abstract}
The first cases of the acquired immunodeficiency syndrome (AIDS), caused by the human immunodeficiency virus (HIV), were recognized in 1981. Today, an estimated 39 million people worldwide are infected with the virus. Sixty-four percent of these individuals currently live in the poverty of sub-Saharan Africa, but the pandemic is now spreading fastest in the largest nations of Asia. A state of food security is said to exist when all people, at all times, have access to sufficient, safe and nutritious food to meet their dietary needs and food preferences for an active and healthy life. A concern for food insecurity arose in the HIV/AIDS pandemic, based on the well-known principles of the interaction of malnutrition and infection; more poorly nourished individuals are more severely affected by infectious pathogens while the ravages of infection tend to deplete the nutritional reserves. The social and clinical consequences of HIV/AIDS endanger access to food in areas already stressed by poverty and environmental deterioration. Interventions related to agricultural productivity, income generation and food assistance, must each be crafted and adapted within the local, community
\end{abstract}

contexts, and recognized as necessary to mitigate the adverse effect of HIV/AIDS on food security. UNICEF has made caring, defined as the provision in the household and the community of time, attention, and support to meet the physical, mental, and social needs of the growing child and other household members, into one of the components of its efforts to promote child survival. Its domain includes care for women, breastfeeding and child feeding practices, psychosocial care, food preparation, hygiene practices, and household health practices. The positive deviance approach, that of identifying household caring behaviors that have the best growth, health and development outcomes in children, is now being applied in the context of HIV-positive children. Stigma is a pervasive factor, which tends to isolate households affected with HIV-positive members, and complicates the social context in which food security and care-related interventions can be delivered. Outstanding gaps in our knowledge of food security-HIV/AIDS relationships have been identified. The research questions include the true effectiveness of food assistance to mitigate the effects of HIV and the interaction of food security status with the efficacy and safety of antiretroviral therapy. However, investigation is somewhat of a luxury within the allocation of scarce financial resources, placing a premium on gathering and codifying useful pragmatic experience for mitigating interventions from the valuable experience currently being gathered on the ground by field workers and communities themselves.

Copyright ๑ 2007 Nestec Ltd., Vevey/S. Karger AG, Basel

\section{KARGER}

Fax +4161306 1234

E-Mail karger@karger.ch

www.karger.com (c) 2007 Nestec Ltd., Vevey/S. Karger AG, Basel

0517-8606/07/0651-0009\$23.50/0

Accessible online at:

www.karger.com/ane
Noel W. Solomons

CeSSIAM in Guatemala

PO Box 02-5339, Section 6163/Guatemala

Miami, FL 33102-5339 (USA)

Tel./Fax +502 2473 3942, E-Mail cessiam@guate.net.gt 


\section{Introduction and Contextual History of the AIDS Pandemic}

On June 5, 1981, the first report of clinical cases of a wasting disease associated with mortality from infections, which was later termed Acquired Immunodeficiency Syndrome or AIDS, was described among homosexual men in Los Angeles [1]. The disease is transmitted by the Human Immunodeficiency Virus (HIV). It is now estimated that the first transmission of the virus from simian species to humans could have occurred some 20 40 years earlier, forming a narrowly circumscribed reservoir in Africa [2]. The subsequent identification of AIDS in the Caribbean, Brazil and sub-Saharan Africa alerted the world's public health community of an epidemic [3].

Humanity has experienced epidemics throughout its history. The bubonic plague (black death) decimated up to one third of the population of Europe during various resurgences from the 11th to the 15th centuries. Lethal epidemics of cholera also tormented Europe prior to the era of John Snow in the mid 1800s [4]. Cholera remains holo-endemic in parts of South Asia to the present day [5]. Smallpox was a worldwide pandemic from antiquity until its eradication in 1979 [6]. Episodic pandemics of influenza have occurred, with the most devastating example in 1918-1919 during the end of World War I; worldwide, some 3 million persons are estimated to have succumbed in the Great Flu Epidemic.

The mobility of populations is one of the crucial factors of person-to-person disease transmission. To this extent, AIDS is probably the first epidemic of the globalized age. Before the era of air travel, moving across distances was much more formidable, and restricted mobility limited the movement of contagious infections. Before electronic communication, moreover, the death and devastation from disease outbreaks, famines and natural disasters did not penetrate the awareness of those outside the affected regions. The earth's population has increased from 2 billion at the turn of the 20th century to a current estimated level of 9 billion plus [7]; hence, many more potential victims of transmissible diseases exist across the globe. All of these are tangible, emerging factors for the context of a contemporary pandemic such as AIDS.

Of the estimated 39 million people worldwide who are infected with HIV, more than 25 million (64\%) reside in sub-Saharan Africa. Unlike their counterparts in the more developed world, people infected with HIV in Africa are less likely to experience years of good health and productivity before the onset of AIDS. Millions of Afri- cans are becoming ill and dying prematurely, not from a lack of advanced medicines, but because of avoidable health problems, most caused by poor nutrition. Currently, HIV/AIDS affects mainly people in the productive age group. This has a great impact on livelihoods and food and nutrition security because it depletes the available labor force [8].

HIV/AIDS is also having a formidable impact on children and advances in child survival. According to Walker and Schwartländer [9], between 1990 and 1998, the number of under- 5 deaths in sub-Saharan Africa caused by HIV infection rose from 2 to $7.7 \%$. Five countries have rates of HIV-attributable under- 5 mortality of above 30 per 1,000, and 16 countries have HIV-specific under-5 mortality rates between 10 and 25 per 1,000 . The rest of the countries in Africa, 18 in total, have rates under 10 per 1,000 [9]. The impact of HIV/AIDS on under-5 mortality in Africa is growing and while not the only cause, it is helping to reverse child survival trends. According to one USAID study, HIV/AIDS is reversing years of economic and social development [10]. The same study cites the fact that in 1990, AIDS accounted for $16.4 \%$ of parental deaths that resulted in orphaning; by 2010, the figure will have increased to at least $68.4 \%$. While these numbers are staggering, they do not take into account children who are living with parents who are ill, who are the primary caretakers for their parents, younger siblings, and others, and children who are responsible for maintaining family livelihoods. Children in Africa face challenges of a scope and complexity never seen before.

On June 26, 1945, the United Nations was born in San Francisco, USA. With its formation, poverty, misery and disease were no longer to be considered the inevitable consequences of the human condition and inequality of wealth distribution could no longer be countenanced as part of the natural, social order. The Declarations of Human Rights was adopted in December 1948 at the Third General Assembly of the United Nations. Its relevance to people living with HIV/AIDS (PLHA) has been the subject of pointed commentary [11]. More recently, the Millennium Goals for health and development have been enunciated, and several of the goals have a direct relevance for HIV/AIDS [12].

These are some of the milestone, historical contexts surrounding the quarter century of the AIDS pandemic. The prism for the majority of health practitioners and public health authorities on any health issue, however, is not at the macro-policy level. Rather, it is down at the community program level or in the day-to-day involvement with patients and clients. We therefore considered 
a community-level focus to be of interest to the readers of Annales Nestlé. 'Food, care and health are widely recognized as the holy trinity of nutrition', commented Haddad [13] at the 17th International Congress on Nutrition in 2001. In our treatment of the topic 'HIV and the Ramifications for Food Security and Child Health in the Affected Communities', we seek to provide insights into the two-way interactions of eating and caring in poor communities in the face of the multifaceted biological, social and psychological impacts of HIV endemicity.

\section{The Interaction of Nutrition and Infection}

Inadequate dietary intake and infectious diseases are the most significant immediate causes of malnutrition [8]. As HIV/AIDS is a complex of a primary virus infection (HIV) associated with opportunistic infections (AIDS), the interaction of malnutrition and infection is fundamental. The US State Department's recent Report on Food and Nutrition for People Living with HIV/AIDS [14] states: 'HIV/AIDS and malnutrition are both highly prevalent in many parts of the world, especially in subSaharan Africa. These effects are interrelated and exacerbate one another in a vicious cycle.'

\section{The Concepts and Principles}

The conceptual and scientific bases for a biologicallevel concern, for food insecurity and an infectious disease such as HIV, were set almost a half century ago. Scrimshaw et al. [15] documented a huge myriad of hostpathogen interactions in nature in which the nutritional status of the host conditioned the response to an infection and the presence of an infection affected nutritional status of the host. This body of data was extended in 1968 in a technical series monograph published by the WHO [16]. On the one hand, a poorly nourished host was more susceptible to becoming infected when exposed to a pathogen, or to having a more prolonged or intense infection that was more likely to be lethal. We now know that the general basis of the nutritional status effect is related to the intactness and function of the host immune defense system. The adequacy of nutrient status could influence the success of host defense against the pathogen [17, 18]. This is true at every level, from the impermeability of the barriers (skin, mucous membranes, intestinal lining) that exclude the entrance of organisms, to the innate responses of engulfing or lyzing organisms, to other ac- quired responses of antibody-mediated reactions and systemic inflammatory response.

On the other hand, an animal or person who suffered an infection, either acute or chronic, could experience weight loss and general deterioration in nutritional status, as well as the onset of specific vitamin or mineral deficiencies. We should note that the classical term for pulmonary tuberculosis was 'consumption'. In general, the ravages of an infection tended to deplete the nutritional status of a host by reducing appetite, blocking nutrient absorption or causing the destruction or wastage of nutrients in the body. For instance, acute dehydration associated with a gastroenteritis attack results from a combination of all of these mechanisms. Moreover, it has long been recognized that an episode of measles often precedes the most severe form of human protein-energy malnutrition, kwashiorkor. Both of the aforementioned nutrition-infection interactions are termed 'synergistic'.

Conversely, in some instances, a well-nourished host showed an increased resistance to becoming infected, or suffered a milder infectious course, whereas an overnourished host was more prone to adverse infections than a normally nourished one. These are instances of a so-called antagonistic nutrition-infection interaction. In the 1950s and 1960s, obesity and nutritional excess were not considered to be important public health problems in either industrialized or developing countries. Although by far the majority of interactions were synergistic, a select number of nutrition-infection relationships were antagonistic in nature; that is to say, the deficiency of a nutrient was protective against infection or the effects of infection by a pathogenic organism $[15,16]$. This generally occurred with intracellular pathogens, those agents of disease that invade the cells of the host and feed on the nutrients within the cytosol. In such cases, the richer the reserves of nutrients in the cells of a host, the more attractive it is to the pathogen, and the more prosperous and successful the invading organism will be.

\section{The Infection-on-Nutritional-Status Synergy in HIV/AIDS}

The most cursory consideration of what we know about the progression of syndromic AIDS will illustrate a classical example of adverse nutritional effects of an infection, with HIV being the primary underlying illness. AIDS is characterized by cachectic wasting [19], and it was termed 'slim disease' in local parlance in the zones in which it was first described on the African continent. 
Moreover, associated infections in the AIDS syndrome stage, including conventional infections such as tuberculosis, as well as so-called 'opportunistic' infections (i.e. organisms that are not usually pathogenic in the normally nourished host), are pathognomonic of AIDS. Due to HIV and its associated infections, a person living with AIDS is an inappetent individual, with grades of anorexia ranging from mild to profound. For instance, Cryptosporidium parvum, a ubiquitous protozoa, which is not usually pathogenic in the immunocompetent individual (or, at worse, causes a self-limited diarrheal episode in a young child), produces a persistent and virtually untreatable intestinal infection, with a diarrheal diathesis that can produce two liters of stool losses daily [20]. AIDS is associated with the chronic activation of the acute-phase response [21], characterized by fever and a metabolic pattern that consumes and wastes macro- and micronutrients, producing visceral and muscular wasting. On the basis of the nutritional depletion effects of HIV in all of its stages, it is essential to supply sufficient nutrients and do what is necessary to help retain them in the body.

\section{The Nutritional-Status-on-Infection Synergy in HIV/AIDS}

Based on the principles of the interaction of nutrition and infection, there was early hope in the HIV/AIDS era that improving the nutritional status of poor and undernourished populations would help to prevent transmission of the virus, either as transmitted sexually among coital partners [22], or vertically from mother to infant [23-25]. The hope for mitigating sexual transmission was raised and examined, despite the original observations that well-nourished homosexuals in affluent nations were the initial spearhead of the AIDS pandemic. In general, the role of vitamin or mineral (micronutrient) supplementation to prevent new sexually transmitted infections has not yielded positive results. Similar aspirations of improving maternal micronutrient status to reduce transmission of the virus from the mother to the fetus, newborn or young infant have been entertained by field intervention researchers; the article by Downs and Cooper [26] reviews the findings from these investigations.

In addition, certain associations between the dietary intake of specific micronutrients and the progression of HIV infections to symptomatic stages and death [27-30] prompted expectations that mitigating micronutrient deficiencies might palliate the infection, reducing its progression or lethality. The nutrient of greatest interest has been vitamin A. The breadth and depth of the experimental intervention designs and findings from field studies related to micronutrients status, micronutrient supplementation and HIV/AIDS outcomes is extensively reviewed by Fawzi [31].

A theoretical, but as yet unexplored possibility in the complex relationship of HIV and host nutritional status would be an increase in virulence of the retrovirus. A model for such a scenario can be found in the work of Beck et al. [32-35] in the USA. They found that a coxsackie-type virus, which produces a mild, transient respiratory infection in well-nourished mice, would be transformed by mutation into a virulent, lethal strain when passed into a mouse host rendered deficient in the trace element, selenium [32]. The mutant virus, moreover, would then become virulent, causing fatal infections in selenium-adequate rodents. It is suspected that the passage of other strains of viruses through hosts with other types of nutrient deficiencies may also produce mutations, increasing their virulence [34]. With widespread human deficiencies of iron, iodine, vitamin A and zinc, among others, in the world, it is urgent to consider - and explore - any transformation potential for HIV in micronutrient-depleted hosts.

\section{The Nutritional-Status-on-Infection Antagonism in HIV/AIDS}

Like all viruses, the retrovirus that causes AIDS is an intracellular pathogen. This would raise the specter of some forms of antagonistic interactions in which depriving HIV of a nutrient critical to its development and proliferation could retard the infection. Moreover, the associated infections in the AIDS syndrome stage, including the so-called 'opportunistic' infections, tend to proliferate in an intracellular location.

This has led to a number of important considerations. One of them concerns the routine fortification or supplementation with a nutrient that could favor the proliferation of HIV or another invading pathogen. In communities affected by the HIV/AIDS endemic, would application of population-wide programs to improve the micronutrient status of the populace at large have a mixed effect? Would it benefit some, for example those who are seronegative for HIV with a preexisting deficit, but adversely effect others, for example those who are seropositive with or without a nutrient deficiency? Such a query takes on increasing relevance with the revelation of the outcome of routine iron and folic acid supplementation (with or without accompanying zinc) to young children in a malaria holo-endemic 
region on the island of Pemba, in Zanzibar, Tanzania [36]. Malaria-infected children in the two treatment arms containing iron and folic acid tended to have more hospitalizations and deaths than those receiving only zinc or in the no-treatment (placebo) control groups.

The flip-side of the issue relates to what Weinberg [37] has denoted as 'nutritional immunity', that is, the potential protection conveyed by a marginally deficient nutritional status in an environment with the transmission of a nutrient-dependent pathogen. Would knowledge of the nutrient requirements of HIV provide a manner to block its proliferation by depriving it of the nutrient? Would the HIV-infected person resist opportunistic infections by being more marginally nourished in the nutrients of interest to the causative bacteria or protozoal organisms?

The aforementioned trace elements (iron and zinc) have been of interest in terms of potential hazards from consuming higher than adequate amounts, raising implications for the safety and prudence of population-level interventions with these nutrients. With respect to iron, a number of theoretical reasons why replete body-iron stores would harbor intracellular organisms, both pathogenic and opportunistic, have been proffered [38]. A recent ironsupplementation intervention trial in Kenya failed, however, to show any adverse effect on HIV load [39].

It has been established that many of the viral mechanisms of HIV are dependent upon zinc. Moreover, in the epidemiological studies of Tang et al., greater progression of HIV to AIDS [27] and a shorter survival through the AIDS phase [28] were observed in the pre-antiretroviral era in men who consumed higher amounts of dietary and supplemental zinc. In a recent clinical study in Durban, South Africa, with some elements of ethical challenge, Bobat et al. [38] tested the hypothesis that administering $10 \mathrm{mg}$ of elemental zinc to juvenile AIDS patients in a KwaZulu-Natal hospital for 6 months would adversely influence the course of the infection. No increased progression nor mortality were observed in the group randomized to zinc; in fact, they showed beneficial responses. The other trial was published by Olsen et al. [39] from Kenya. HIV-1 viral load was monitored over 4 months of supplementation with twice weekly $60 \mathrm{mg}$ doses of iron to seropositive pregnant women. There was no effect on viral load from this semi-weekly iron. Since 60-120 mg of iron daily are the common dosages in the prenatal situation, however, the authors comment that 'effects of higher doses of iron cannot be excluded' [39].

The results of the aforementioned trials can be interpreted as providing some assurance for the safety of including HIV-positive children into the coverage of iron
Table 1. Position Statement of the American Dietetic Association and Dietitians of Canada on nutritional intervention in the care of persons with human immunodeficiency virus infection

Infection with the human immunodeficiency virus (HIV) and the development of acquired immunodeficiency syndrome (AIDS) have had a significant impact on domestic and global health, social, political, and economic outcomes. Prevention and treatment efforts to control HIV infection are more demanding than in previous decades. Achieving food and nutrition security, and managing nutrition-related complications of HIV infection and the multiple aspects of disease initiated by or surrounding HIV infection, referred to as HIV disease, remain challenges for patients and for those involved with HIV/AIDS prevention, care, and treatment efforts. Confounding clinical issues include medication interactions, coinfection with other infections and diseases, wasting, lipodystrophy, and others.

From Fields-Gardner and Fergusson [44].

or zinc supplementation or fortification programs. However, the theoretical considerations of interactions of iron and zinc with HIV or other infecting organisms in the AIDS syndrome $[39,40]$ militate in favor of continued vigilance and monitoring for any indications contrary to those in only two respective trials.

\section{Food Security and Insecurity in HIV/AIDS-Affected Communities}

In 2001, the then head of UNAIDS, Dr. Peter Piot, stated that the most insistent concern of the PLHA, whom he had visited, was that of having enough food [41]. Whiteside et al. [42] point to an important reality regarding the time frame, in that the long incubation period between infection and illness has a series of consequences; it means that it takes time for HIV infections to turn into AIDS cases, and AIDS cases to translate into deaths with all the consequences of orphaning, poverty and changing population structures'. However, now that we are 25 years into the HIV/AIDS epidemic, we can begin to examine these consequences in the context of the effect on food security of affected populations. A troubling contention is made by Tabi and Vogel [43], nursing investigators working in Ghana: 'In Ghana, like many developing countries, more patients with HIV and AIDS die because of their poor nutritional status than from the disease itself'. Although coming from the two most affluent nations of North America, the text of the 2004 position statement of the dietetics associations of the US and Canada (table 1) [44] 
conveys the comprehensive and global grasp of issues that impact food security and child care across the world in the 21 st century.

\section{Definitions of Food Security and Measurement of Food Insecurity}

According to the Rome Declaration and World Food Summit Plan of Action of the Food and Agriculture Organization, a state of food security exists 'when all people, at all times, have access to sufficient, safe and nutritious food to meet their dietary needs and food preferences for an active and healthy life' [45]. A state of 'food insecurity' would be a situation in which the aforementioned, definitional criteria are not met. A short hand definition is 'limited or uncertain access to enough nutritious food' [46]. The loci of concern for food security can be various, including at a national, local (community), family (household) and even the individual level. It is logically based on the amount of food available at the various levels. Furthermore, with an uneven distribution of an insufficient food supply, some of the people could satisfy their food security, but its equitable generalization to 'all people' would require that enough food were present in a country to cover the needs of all of its residents.

Various institutions and individuals have attempted to operationalize the definitions into formats to assess food security and to diagnose a state of insecurity. The Food and Agriculture Organization in the UN System collects and tabulates food balance sheet data on most countries, from which it can determine a state of 'undernourishment' in a nation, when the number of calories of food energy produced or imported is insufficient to cover the needs of the population. The FAO has generally insisted on a minimalist definition, based on the minimal, essential ration [45]. Others are more elaborate and ambitious in their demands. Gopalan [47] for example comments: 'The achievement of nutrition security at the household level involves adequacy of food supply at the national level and equitable distribution of food among the population in accordance with their physiological needs'.

For most practical and research terms related to HIV/ AIDS, the household (or individual) level would be the most appropriate locus of concern for food security. Instruments to evaluate food security in the field setting date back to the early 1990s [48, 49], including the collection of information about demographic characteristics, frequency of fruit and vegetable consumption, and household
Table 2. Further research needs on assessing food security and food insecurity

1 How well measures of household food insecurity designed for chronically food-insecure contexts capture the processes leading to, and experience of, acute food insecurity

2 The impact of short-term shocks, such as major floods or earthquake, on household behaviors that determine responses to food security questions

3 Better measurement of the interaction between the severity and frequency of household food insecurity behaviors

4 The determination of whether an individual's response to survey questions can be representative of the food insecurity experiences of all members of the household

From Webb et al. [54]

food supplies. Cross-validation against other indicators of food insufficiency in rural US households found high degrees of both sensitivity and specificity in the diagnosis of food insecurity. On another front, dietary diversity is proposed as a possible indicator of food security and predictor of nutritional status, but there is need for further research to standardize definitions and methodology before it can be applied widely [50]. To date, additional tools to measure food security at the household level have been advanced; these tools are reliable in population-based surveys, and some studies have found that measures of food security are associated with nutrient intake [51].

Despite the validation and construct validity of field questionnaires in certain settings, the assessment of 'food insecurity' is not without its paradoxes. Rose [52] examined food security indicators in a nationally representative sample of the US population and found that most members of households classified as food-insufficient (but curiously not the preschool-aged members of the families) reported lower daily intakes than those in foodsufficient homes, but this pattern did not apply to household members in the preschool age. Moreover, the prevalence of childhood overweight status is increasing. Greater food insecurity has been associated with child overweight status in girls aged 12-17 years, as measured by the US Food Security Scale [46]. Using the same instrument in rural Malaysia as validated in New York State [48, 49], however, Shariff and Khor [53] also registered the apparently paradoxical finding of more overweight and obesity (50\%) in food-insecure women as compared to $38 \%$ of women in food-insecure households. Increased waist circumferences followed the same association. 
As a consequence, there has recently been a reformation movement to revisit the goals of food security assessment, its conceptualization and measurement [54]. The overview highlights three main conceptual developments associated with practical approaches to measuring constraints in access to food: (1) a shift away from using measures of food availability and utilization to measuring 'inadequate access'; (2) a shift away from a focus on objective to subjective measures, and (3) a growing emphasis on fundamental measurement as opposed to a reliance on distal, proxy measures. Webb et al. [54] outline a fourpoint agenda (table 2) for development and refining measurement of food security. Given the paradoxical elements of the traditional approaches outlined above and the richer conceptual depth, this new approach, once developed, would seem to offer more promise and application in relation to the impact of HIV/AIDS.

\section{Vulnerability of Poor Communities}

Poor communities in developing countries are at the greatest risk of an increased incidence and prevalence of AIDS $[55,56]$. Poverty also conveys vulnerability to inadequate food intake, impaired nutritional status, and limited health care $[57,58]$. The transmission of HIV over these fragile circumstances of rural and urban poverty has completely overwhelmed and/or shattered coping mechanisms that existed prior to the advent of the AIDS pandemic.

HIV and AIDS affect all elements of society, not just those directly infected and living with the virus. It also has other unique characteristics as outlined by Whiteside et al. [42]: 'the long incubation period between infection and illness means that it takes time for HIV infections to turn into AIDS cases, and AIDS cases to translate into deaths with all the consequences of orphaning, poverty and changing population structures. Furthermore it means that once the HIV prevalence has peaked, AIDS impact will take years to work through - this epidemic is a "longwave" event. Therefore, an intergenerational and lifecourse perspective is important in dealing with the local manifestation of the pandemic.' At least for Africa, where the greatest number of PLHA are found, food insecurity is also extremely problematic, with a most grim forecast made regarding persistent and expanding poverty. According to Rukuni [59], 'Africa remains the only region in the world where the number of hungry people will still be on the increase in 2020, and the number of malnourished children will have increased correspondingly'.
Table 3. Consequences of the loss of productive labor force on agricultural productivity

1 Reduction of land use under cultivation, as people are physically unable to work in the field

2 Reduction in crop yields, due to delays in carrying out certain agricultural interventions such as changes in cropping pattern

3 Changes cropping patterns as some families have been known to switch to less labor-intensive crops

4 Decline in the range of crops per household in AIDS-affected families reduce the number of crops under cultivation to one staple crop

5 Reduction in the ability to control pests such as through weeding and other inter-cultivation measures due to shortage of labor

6 Loss of agricultural knowledge and farm management skills, due to loss of one or both parents to AIDS

7 Decline in livestock production as the urgent need for cash may force some families to sell animals

Modified from Saasa [60].

\section{Factors Conditioning the Food Security of People Living with HIV/AIDS}

Whatever the caveats and limitations to the precise measurement of food insecurity might be, the following represents a review of conditions and factors within environments and societies that threaten or protect communities' food access and availability. The intersection of these factors with HIV-infected individuals and/or households is a matter of incipient academic study.

\section{Human Capital Losses and Agricultural Productivity}

The amount of food available in a country is a product of agriculture and horticulture or international trade. With respect to trade, the ability to import depends on the wealth generated by exports, which is a function, in turn, of the natural and human resources converted into goods and services of value. With regard to agriculture and horticulture, the scale of production varies from large-scale extensions to family subsistence plots. At whatever level, HIV/AIDS has had a series of adverse consequences on agriculture activities. Saasa [60] has listed these consequences from the perspective of an African experience (table 3 ).

The first consequence listed in table 3, namely the reduction of human assets in terms of labor and consequent 
reduction of land use, is the most commonly mentioned. As commented by Rutengwe [8]: 'Currently, HIV/AIDS affects mainly people in the productive age group. This has a great impact on livelihoods, food and nutrition security because it causes shrinkage of the available labor force.' Available labor is further diminished as healthy individuals have to care for those infected and attend funerals for those who have died. Children are forced to leave school early, thus achieving lower levels of education. Additionally, with the premature death of adult workers, there is a loss of indigenous knowledge between generations, as well as 'learning by doing' while being supervised by someone more experienced. According to the FAO of the United Nations, more than seven million agriculture extension workers in $25 \mathrm{sub}$-Saharan countries have died, and 16 million more are expected to perish in the next two decades.

Debilitation of a work force by HIV/AIDS can adversely effect a nation's capacity to produce its own and/or import food. Several other consequences can be illustrated with examples from the recent literature. As early as 1993, only 12 years into the HIV/AIDS epidemic, a retrospective study in the two most fertile districts of Uganda documented a land-use decline in $66 \%$ of surveyed households, with corresponding 11 and $32 \%$ declines in poultry and cattle production, respectively, ascribed to poor management [60]. The most frequently reported reasons for crop reductions were death and sickness; these were estimated as affecting $8 \%$ of families with children under 5 years of age in the study area. In this setting, moreover, poverty has decreased the use of pesticides, herbicides, and fertilizers [61].

As Gillespie et al. [62] describe, the advent of HIV/ AIDS has brought about other impacts on land use, including the cultivation of less nutritious crops (e.g. some tubers) that require less labor. Although not farming the land will make it more fertile for future crop growing, assuming the family can afford to do so, families may become more vulnerable to losing land rights, particularly women and orphans. Natural and physical capital is lost as families are forced to sell productive assets (i.e. equipment and tools) and livestock to pay for medical and funeral expenses, rendering the ability to return to agricultural work nearly impossible. In addition, other forces at work negatively impact agricultural productivity, including overpopulation and subdivision of land by inheritance as seen in Uganda [61].

In a related facet of the agricultural productivity issue, the exigencies of the rural agrarian lifestyle, with domestic chores that are labor intensive and time limiting, have also been identified as a barrier to Ethiopian women's participation in education for the prevention of sexually transmitted diseases [63].

\section{Household Issues in Obtaining Food}

Women are part of the workforce in both rural and urban AIDS-endemic African settings. In a study of married women in Malawi, Zimbabwe, and Zambia, examining factors affecting maternal nutritional status in HIV/ AIDS-affected and drought-prone areas [64], geographically variable findings were obtained. The risk of chronic energy deficiency (CED), as defined by having a body mass index of $<18.5 \mathrm{~kg} / \mathrm{m}^{2}$, was greater in women in Malawi with less family decision-making power, as well as in urban women in Zambia. In Zimbabwe, no association between body composition and decision-making power was found. The author's conclusion was that 'women with both low input and CED may lose productive capacity, potentially putting them at greater risk of food insecurity and HIV/AIDS in high prevalence settings' [64].

Household food security can be compromised due to a lack of financial resources and infrastructure, and faulty household resource allocation among poor South African farm-worker families, even in the absence of parental infirmity [65]. The resulting insecurity impacts negatively, especially on children, with half of them being underweight, stunted or wasted. These data come from a study that highlights destitute living conditions of farm-worker families in farming communities of North-West Province of South Africa [65], but is not atypical of situations throughout sub-Saharan Africa.

Social margination and stigma, singling out individuals and their families for discrimination and avoidance, are factors in reducing a household's capacity to obtain food. The stigma of AIDS infection varies from community to community and society to society $[63,66-70]$, but there is a general shunning of affected individuals. Even if individuals have the physical capacity for productive work, there is a differential exclusion of HIV-infected individuals from the workforce [67], while neighbors and consumers may eschew their home-produced products. Within an otherwise poor society, families living directly with HIV become the poorest of the poor, limiting their access to financial resources to provide food and other basic necessities to the family [66].

As previously discussed, human capital losses are devastating to agricultural production. The same is true in subsistence economy settings. Cultivating individual plots of land to produce food for household consumption becomes increasingly difficult as the health of the infect- 
ed household members deteriorates, debilitating health, strength and energy [71]. Field activities cannot be given attention and the lands become fallow.

In addition to human, natural, and physical capital losses, households also suffer major financial capital losses. The combination of stigma-related issues with regard to the rejection of formal bank credits and group-based microfinance initiatives, in addition to difficulty in obtaining day laborers, causes additional financial stress for HIV/AIDS-affected households. As a desperate measure, households are forced to borrow from informal money lenders who charge exorbitant interest rates [62].

With respect to the financial burdens imposed on PLHA, some case-study data are illuminating. Expenditures at the household level attributable to AIDS up to death were USD 836 per case in a 2004 publication from Chad [72]. Expenses related to productivity losses made up $28 \%$ of total costs. More than half the total costs (56\%) were health care-related expenditures, with funeral costs contributing $16 \%$. AIDS cases relied more often on the borrowing and selling of household assets than controls for treatment. Household expenditures of AIDS patients were much higher than control households mainly due to health-related outlays.

\section{Household Issues with Infant and Young Child \\ Feeding}

In terms of infant and young child feeding, whereas there is no apparent monetary cost for maternal milk, the energy requirements for lactating mothers increase by approximately $500 \mathrm{kcal}$ compared to non-pregnant, nonlactating woman of the same age [73]. Although no additional requirements for lactation beyond the adjusted demands of HIV have been established [74], if the availability of calories for basic sustenance is a problem, getting additional food to adequately support an additional $500 \mathrm{kcal}$ for lactation can represent the 'tipping point' for a household's financial coping mechanisms.

If obtaining extra food for the mother is a challenge, paying for special foods for the infant is even more prohibitive. In the poorest communities, suitable artificial formulas may not be available for sale and, if available, may not be accessible and affordable to the households choosing this option as a response to maternal HIV infection [75]. Should a mother choose against breastfeeding and opt for a breast milk substitute formula-feeding, the aggregate cost of formula and supplies poses a substantial burden on household resources. Given the sanitation limitations, moreover, the safety of formula prepared in precarious hygienic situations has been a concern [76], projecting more diarrheal episodes in children. This imposes more efforts in child care, costs for medications, and an enhanced risk of infant mortality, adding to the overall 'costs' of not breastfeeding. Finally, any special investment in formula for the infant constrains the resources for feeding older siblings.

The provision of 'weaning food' is the next stage of child dietary evolution in which food security can intercede. The diets offered to infants in poor households to complement or substitute for breast milk are monotonous and bulky, and rarely cover the shortfall left by breast milk in providing the energy and nutrients required to support rapid growth, build nutrient stores and assure resistance to infection [50]. The pattern of growth and prevalence of malnutrition observed from birth through the first 5 years in sub-Saharan Africa are suggestive of nutrient inadequacies of the diet and the experience of infection.

\section{Dietary Consumption of Persons and Communities Living with HIV/AIDS}

The issues of dietary consumption as related to food insecurity and biological metabolism are diverse. Survey results on dietary adequacy vary depending upon the setting. For instance, in Boston, Mass., USA, the dietary adequacy of both macro- and micronutrients, based on quantitative assessment of 3-day diet records, was generally acceptable among intravenous drug abusers who were both HIV-positive and negative; there was no distinction between the two subgroups [77]. Equivalency of intakes, however, may not be sufficient, given a documented nonequivalence of nutrient demands. According to the WHO [73], HIV-positive individuals have a $10 \%$ higher energy requirement to maintain weight and physical activity, while those with symptomatic infection have $20-30 \%$ higher energy needs to support adult weight maintenance. A lower body mass index of the HIV-positive group was attributed more to the metabolic demands of the disease than to dietary-restriction factors [77]. It is estimated that, for children, there may be a $50-100 \%$ requirement of additional energy to restore lost weight [73].

In addition, a new study released by HIV Medicine found that malnutrition at the time antiretroviral therapy begins is associated with significantly poorer survival. Patients with malnutrition had a sixfold increase in death compared to patients with good nutrition [78]. HIV and malnutrition work together in a vicious cycle that weak- 
ens the immune system and the body through repeated infections.

Dietary intake in HIV-infected patients is not without its paradoxical aspects, however. Kim et al. [79] surveyed a US population of HIV-infected adults. Twenty-three percent were dieting for weight loss. Non-whites and injection drug users consumed less energy than whites or non-drug injectors. Women without nausea and vomiting consumed more energy. A significant proportion of the study cohort (52\%) were consuming less than the recommended dietary allowance of vitamin A and $11 \%$ had inadequate protein intake. It is clear that the current literature on dietary intake is focused in affluent countries, and more empirical findings from developing country settings are needed.

\section{Myths and Paradoxes in the Relationship of Food Insecurity and HIV/AIDS}

A number of myths and paradoxes revolve around the topic of food insecurity and HIV/AIDS. It is important to recognize them, and not allow them to confuse policy and program.

\section{Addressing the Myths}

Conflict situations, such as that in the Ivory Coast, have been shown to disrupt the health care system and interfere with efforts to prevent transmission of HIV and to bring care to infected persons [80]. What will food insecurity mean for the transmission of the disease? In an analysis from the United Nations High Commissioner for Refugees, Spiegel [81] asserts that: 'conflict, displacement, food insecurity and poverty make affected populations more vulnerable to HIV transmission. However, the common assumption that this vulnerability necessarily translates into more HIV infections and consequently fuels the HIV/AIDS epidemic is not supported by data.' If this be true, resolving food insecurity issues that are the subject of this review can clearly be palliative, mitigating the suffering of the infected. It will not, however, make a contribution to stemming the advance of the viral transmission, itself.

\section{Grappling with the Paradoxes}

As discussed earlier, measures of household food insecurity can be associated with obesity. Similarly, despite the 'slim disease' image of AIDS, environmental, behavioral and medication factors can favor states of excess weight. In the urban regions of Africa, the background of overweight may be becoming the context for the extension of HIV/AIDS. In the Transition and Health during Urbanization of South Africans study, urbanization in the North West Province of South Africa was found to be accompanied by an improvement in micronutrient intakes and status, but also by increases in overweight, obesity and several risk factors for non-communicable diseases [82]. The increasing emergence of non-communicable diseases in black South Africans, compounded by the HIV/AIDS pandemic, presents a complex picture for health workers and policy makers [83].

The factor is the extension of anti-HIV medication to the poor. Adverse effects of certain therapies for HIV and associated infection disorders increase the risk of developing diabetes, obesity, and the metabolic syndrome; as such, therapies should be carefully chosen, particularly considering cardiovascular disease risk [84]. Researchers in Philadelphia, USA [85], make the interesting conjunction: (1) that obesity predisposes people to diabetes and cardiovascular disease, and (2) that these are also the complications associated with HIV, its treatment or both. They found that, in the therapeutic era, obesity (14\%) and overweight (31\%) were more common than wasting (9\%) in their clinical population in Philadelphia [85]. Among the female subgroup, the prevalence of obesity was $28 \%$. The prevalence of central obesity was $45.7 \%$ in a group of persons taking highly active antiretroviral therapy to control HIV infections in Sao Paulo, Brazil, and it was associated with greater consumption of lipids; for every increase of $10 \mathrm{~g}$ in lipid intake, the odds of central obesity increased 1.3 times [86].

\section{Policy and Program Responses to Food Insecurity Affecting PLHA, Their Families and Communities}

Rosegrant and Cline [87], in their prominent 2003 article in Science comment: 'Global food security will remain a worldwide concern for the next 50 years and beyond. Recently, crop yield has fallen in many areas because of declining investments in research and infrastructure, as well as increasing water scarcity. Climate change and HIV/AIDS are also crucial factors affecting food security in many regions.' The WHO Consultancy on nutrient requirements for PLHA underscored an 'urgent need for renewed focus on and use of resources for nutrition as a fundamental part of the comprehensive packages of care at the country level' [74]. Food security is diminished when underlying food systems are stressed [88]. Among the 'tipping points' are elements of 
environmental change, including conflict situations and HIV/AIDS; these may be particularly severe when the factors occur in combination, such as in southern Africa during the past decade. Hence, it is important to consider aspects of food insecurity at the global, national, community and household/individual level in the context of the HIV/AIDS pandemic.

\section{General Policy Considerations in Mitigating Food Insecurity}

To the extent that policy options and programmatic operations are increasingly expected to rely on a base of evidence of their efficacy, safety and efficiency, the search to date for that evidence has not satisfied everyone. The US State Department report comments: 'Even though there are increasing numbers of interventions to address food insecurity in high HIV/AIDS prevalence settings, there is little empirical evidence of the effectiveness of such programs in improving nutrition and health outcomes or sustainable access to utilization of foods by targeted populations' [14]. One quickly becomes convinced by context and experience, however, that the search for generalizable measures may be futile, and that, like politics, most of the guidance for addressing HIV/AIDS is local.

Gillespie [89] has summarized the three overriding and guiding principles for a comprehensive strategy toward addressing the food insecurity issues that arise in the context of HIV/AIDS. They include: (1) strengthening household and community resistance to HIV and resilience to AIDS; (2) sustaining and enhancing livelihood opportunities in affected communities, and (3) ensuring appropriate social protection. He cautions, however, that the mobilization should not be separate and detached specifically for the HIV/AIDS crisis, but rather to build the solutions across whole communities. A similarly cross-cutting philosophy is offered by Saasa [60], who issues a call to resolve the underlying problems of poverty and stagnant development in rural areas of affected countries, especially in sub-Saharan Africa.

According to Gillespie et al. [71], the policy principles include: targeting of resources; attention to scope and scale; joining with appropriate partners in collaboration; planning and programming for superimposed emergencies, and monitoring and evaluation. As to specific interventions relevant to food security within the HIV/AIDS epidemic, directed strengthening in the sectors of agriculture, home and community gardens, food aid, water, sanitation and environmental health, and communitybased natural resource management are the priorities to pursue $[90,91]$.

HIV, Food Security and Child Health
Accordingly, a concerted focus on poverty and inequality in HIV/AIDS-affected societies will serve to address the consequences of the infection. This is referred to by Gillespie $[90,91]$ as the 'mainstreaming' of HIV/ AIDS, making its redress part of the redress of community problems. This is one of the tactics to act effectively without stigmatizing the beneficiaries. It can be advanced by providing appropriate capacities and inducing their application with reasonable incentives [90, 91].

\section{Agricultural Support and Development to Mitigate \\ Food Insecurity}

In the broadest sense, agricultural intervention would include home and community gardens as well as the cultivation of crops and animal husbandry to provide both income and nutritional sustenance. Horticulture is focused on dietary diversity and enriching dietary intake with essential micronutrients. As gardening may be new to a community, efforts must be put into building community capacity to implement gardens, as well as behavior change focusing attention on the need to consume the nutrient rich, locally produced food.

Subsistence farming can be sustained if crops requiring minimal care or labor-saving measures, such as introducing animals for tilling the soil, come to replace the traditional cultivation [71]. Diversifying production and introducing agricultural technologies that reduce labor use or bottlenecks (e.g. no tillage) also will help to reduce burdens on human capital. Labor burdens can also be reduced by introducing appropriate technologies, such as small-scale, labor-saving, food-processing technology, fuel-efficient stoves and water pumps. Improvement and adaptation of agricultural systems through research and development appropriate to the settings has been advanced by Parley et al. [92] as a way to make countries more self-reliant, and communities more resilient. They call for investment in new technologies suited to food production in developing countries. Microfinance options can also be introduced to pay for operating expenses to fund draught animals, inputs, hired labor, etc. Communities should also be encouraged to share practical knowledge and experience in agriculture with widows, orphans, and other survivors, as well as include agricultural training in school curriculums.

\section{Direct Food Assistance to Mitigate Food Insecurity}

The principal argument that militates in favor of feeding relates to the humanitarian principles of getting sustenance to malnourished people. In areas in which antiretroviral therapy is scarce, overcoming dietary intake

Ann Nestlé [Engl] 2007;65:9-28 
Table 4. World Food Programme options for the use of food aid in the mitigation of HIV/AIDS

1 Food for vocational training for street children and orphans

2 School feeding with special take-home rations for families caring for orphans

3 Food-for-training programs which promote income-generating activities (mushroom growing, tie-dying, etc.) and are linked to small-scale credit facilities for women and other orphans

4 Food-for-training and food-for-work to support farmers through animal traction schemes and the provision of seeds and agricultural tools

5 Food-for-work to support increased agricultural production through home gardening to improve diet diversification and increase intake of micronutrients

6 Food-for-work and food-for-training to support the introduction of small-scale, low-labor livestock activities to (a) increase the intake of high energy, high protein food, and (b) provide capital/savings that will increase over time.

Modified from Gillespie et al. [71] as adapted from the World Food Programme [94].

deficits would have a clear palliative benefit as summarized by Tabi and Vogel [43]: 'The health and nutritional status of the patients can be improved through nutritious food, allowing them to lead longer and better quality lives'. Nutritional support is seen as having the potential to prolong the lives of individuals, both for their own benefit and for those dependent upon them for care [71].

Direct food aid has long been seen as the 'third rail' of development assistance by some who argue that it has a penchant to create dependency and disrupt agricultural markets. The reality of HIV/AIDS in poor countries, however, is that it has already brought such dependency and disruption. The question is therefore how best to utilize food aid in mitigating the effects of the epidemic. Kadiyala and Gillespie [93] have recently reviewed in detail the potential of food assistance. They put it, first and foremost, into the context of a social safety net. As recognized by the US State Department: 'Food aid interventions can have a positive impact on beneficiaries' lives by reducing their dependency on dangerous and livelihood-eroding coping strategies and by improving diet diversity and quality, as well as household food security' [14]. Rukuni [59] voices a similar prodding to governments to invoke complementary food security policies that increase the probability of food being accessible to vulnerable groups.
If indeed direct food assistance is a useful component of a safety network, both caveats and creativity come into play in its implementation. Food aid should generally target areas of a country that are the most food insecure and in which households cannot meet their food needs [71]. Organizational food distribution, moreover, should avoid undermining household and community coping and development strategies [71]. In this earlier review [71], the ideas of the World Food Programme [94] for incorporating food aid as assistance to achieve educational and productivity ends (table 4), while supporting nutrition of the food insufficient, were brought under the loupe of HIV epidemic. Most recently, Kadiyala and Gillespie [93] have come to view food assistance in terms of the broader context of protecting livelihoods. Apparently, there is increasing openness to exploring increasing creative uses of food aid. Communities are complex social entities; one precaution, however, is to avoid obvious targeting of beneficiaries, where stigma exists for the basis of that need [95], which is generally the case with HIV. In the end, however, there are those who chant the familiar refrain that food aid must include an 'exit strategy' to avoid permanent dependency [14].

\section{Principles of Intervention Programming on the Local Level}

There is insistent critique and criticism of the limited scale of the extant programs such as: 'When organizations have conducted interventions to improve food security in HIV/AIDS endemic areas, the projects have tended to be isolated and small-scale and the results not generalizable' [14]. In part, perhaps, they are small for attempting to follow the prudent guidance to focus in areas of greatest existing insecurity $[8,71]$. They are isolated because the most affected communities are isolated, both by geographical remoteness and social stigma. However, if the principles of community empowerment and responsibility are operative, the interventions will not be 'protocols' as communities will find their way within particular circumstances that are, at the same time, changing circumstances.

In their treatise on global food security, Rosegrant and Cline [87] stress the fundamental human right of communities to have involvement in all steps of program targeting as elemental to good democratic governance. The importance of local program development, synthesizing the particular complexities of a community for operational research into action, are also emphasized by Rutengwe [8]. The study found that the interaction of chronic urban household food insecurity, prevalence of malnutri- 
tion and income poverty was the major problem. The study also found that an interactive approach, using a problem tree and solution tree approach, for example, to logically analyze the causes and effects of the situation in a given area has provided a useful pathway to formulate local actions with a maximal input from community stakeholders.

\section{Delving for Solutions at the African Forum 2006}

Theoretical principles and academic findings leave us short of practical solutions for communities and individuals confronting food insecurity. An example of the pragmatic and ongoing steps being taken to glean lessons from the field by sharing experience of frontline health professionals was a meeting held in Lusaka, Zambia, in May 2006, convened and coordinated by Project Concern International. Entitled 'The African Forum 2006: An Integrated Response to the Dual Epidemic of HIV/AIDS and Food Insecurity' [96], the Forum sought to provide participants with the opportunity to share first-hand experience in grappling with the difficult issues of the dual epidemics, and in designing and implementing integrated programs. Over the course of the week, participants shared their expertise, and learned practical solutions for improving food and livelihood security in their own communities. Participants also identified priorities and changes needed at all levels in order to make integrated HIV/AIDS and food security programming a reality. These ideas and frontline observations are captured in the Africa Forum 2006 Declaration.

The Forum sought to build field staff capacity around integrated programming by facilitating peer learning, motivating and empowering practitioners through concrete examples of successful community responses to challenges from the dual epidemics of HIV/AIDS and food insecurity. Learning was based on adult education and behavior change principles. Adult learners need to be actively engaged for learning to take place, building upon what they already know. This is especially true of field staff, who are people of action, requiring dynamic, handson and skills-oriented learning approaches. During the Africa Forum, each participant was expected to be both a learner and a contributor. This meant that each participant had to be present in one form or another, as well as actively participate in hands-on learning activities around a particular aspect of integrated HIV/AIDS and food and nutrition security programming. Participants learned by getting their hands dirty, for example digging gardens, preparing food, and visiting community projects.

HIV, Food Security and Child Health
The Forum [96] addressed practical challenges confronting counselors in implementing the best practices for infant and young child feeding, for example. A specific barrier to adhering to exclusive breastfeeding and rapid weaning protocols are those of stigma and cost. In Zambia, community gardens have been spawned for improving diet quality, beyond mere energy satisfaction, in accord with the broader concern stressed by Gopalan [47]. A number of horticulture projects were illustrated at the Forum, manifesting the multiple potential of food security, improved nutrition and enhanced livelihoods. An example of this holistic, synergistic purpose is a Malawian project, 'Improving Livelihoods through Improved Food', which combines a food security agenda with environmental, educational and health components at the household level in HIV-affected communities [96]. Expanding the integration concept to a synergy with incipient drug therapy initiatives, it was a consensus at the Forum that participating in drug therapy initiatives without adequate quantity and quality food extends fewer lives [96].

Agriculture itself was seen in the Forum [96] in an integrated context, with experiences of produce production for income generation being shared. In Zambia, widows' groups had banded together to raise mushrooms for commercialization, to increase household food security. Beekeeping for honey production was another income-generating activity illustrated, as was animal husbandry.

Not all food security problems can be resolved at the agrarian level. Governmental and nongovernmental agency 'safety nets', which may involved cash transfers and food distribution to struggling families, are considered part of an integrated solution. As noted, Marchione [95] has admonished programming to try to avoid the pitfalls to targeting specific assistance at the community level, both for the stigma that can befall the recipients and the resentment that can arise in the unentitled segments of the population.

\section{Care and Caring for Child Health}

\section{Child Caring and Traditional Health Practices}

The health of children, both infected and uninfected by HIV, and both orphaned and living with parents, will depend not only of food and nutritional security, but also on the quality of care they receive. Care, in turn, is a function of the resources available in the community and the household (including energy and time) and of the caring 
Table 5. The six categories of care practices

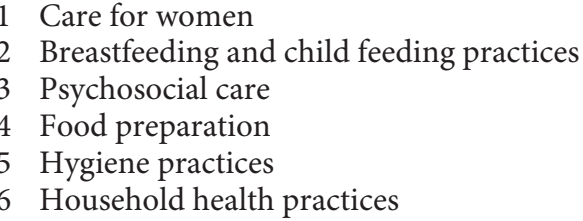

After Martin-Prevel [97].

behaviors and decisions of the caretakers. The poorer the environment, the more important 'care' becomes in supporting children's survival, growth and development.

The UNICEF conceptual framework for nutrition was devised in 1990 and adopted at the International Conference on Nutrition in Rome in 1992. It recognized three underlying factors of child survival, growth, and development $[97,98]$. The first two were household food security, and health services and environment. The third element of the triad was caring: 'Care is the provision in the household and the community of time, attention, and support to meet the physical, mental, and social needs of the growing child and other household members'. According to the refined theory, enunciated by Martin-Prevel [97], care resources at the household level have been described according to three categories: human (knowledge, beliefs, education, physical and mental health of the caregiver); economic (control of income, workload and time), and organizational (alternate caregivers, community support).

Martin-Prevel [97] has disaggregated and prioritized the specific elements of care. There are six categories of care practices as listed in table 5. In general, it is assumed that the mother is the primary caregiver for children. As one can see, all six are vitally essential to child health in the HIV/AIDS era. The practices first protect the caregiver, and then mediate the nourishment of the family and the mitigation of the health-averse factors in the environment.

Urban areas of the Indian subcontinent are among zones experiencing the most rapid expansion of the HIV/ AIDS epidemic. It is important to recognize that the nutritional status of slum children is worst among all urban groups and is even poorer than rural averages [99]. This is aggravated by the lack of proper child care practices. Moreover, just as with food security, the background of poverty predisposes to precarious child caring, and the additional burden of the AIDS epidemic creates severe stress on an already fragile situation.

\section{Orphans and Non-Parental Caretakers}

Orphaning is an unfortunate outcome of rampant, lethal HIV/AIDS disease circulating among the adult generation. It is a major risk factor for ill health and undernutrition of the children in a community. Commenting on children orphaned by AIDS, Shetty and Powell [100] state: 'Internationally, the orphan crisis caused by the Human Immunodeficiency Virus/Acquired Immunodeficiency Syndrome (HIV/AIDS) pandemic remains a serious issue with long-term social consequences. At the end of 2001, an estimated 14 million children worldwide had lost their mother or both parents to AIDS or related causes. Sub-Saharan Africa is the most severely affected, accounting for more than $80 \%$ of those orphaned as a result of AIDS.' Without the care of parents or an appointed caregiver, children are likely to face extraordinary risks of malnutrition, poor health, inadequate schooling, migration, homelessness, and abuse [100].

Estimates put the number of children orphaned today in Uganda primarily due to AIDS at two million [101]. In the northern part of the country, it is argued that the consequential transformations in fostering practices must be historically situated through a focus on the effects of armed conflicts and uprooting of the local pastoral and cotton-based economy, which have occurred since the late 1970s [101]. These processes jointly produced dramatic economic marginalization with highly disturbing consequences for orphans and their caretakers. In an anthropological study in rural Kenya, Nyambedha et al. [102] found the inability of orphan households to afford school fees to be the most pressing perceived limitation, although lack of food, medical care and clothing were also prominent. The traditional, kinship-based support systems made a major contribution to catering for orphans though the resources were far from enough. In observations from southern Africa, just the presence of parents reduces a child's risk of being underweight from 39 to $21 \%$; children with two living parents had only a $10 \%$ risk of being underweight [12].

\section{Reforming Caring Attitudes and Practices}

It seems pretentious to some that professionals from a Western and affluent persuasion should be criticizing and endeavoring to 'reform' the attitudes and practices regarding child care in non-Western, low-income societies [103]. To decide which are 'good' traditional caring practices to be conserved, and which ones should be 'improved' would seem to be the height of pretense. They 
would call for a blanket respecting of the traditional approaches to care, which, they argue are 'tried and true', the product of eons of societal evolution and adaptation embodying cultural wisdom. Who are UNICEF, anthropologists or academics to impose a new caring agenda on a community?

Indeed, the cultural evolution of societies has given rise to the traditional caring practices for children, such that the evolutionary imperatives are relevant to understanding their origins and consequences for child health. According to Darwinian Theory, it was not in the evolutionary intent for all those born to survive. The tracts of terrain available to the nomadic clans could only support a certain, restricted number of foragers and hunters, such that numerical stability, rather than expansion, was in the evolutionary interest for the survival of the tribes, and hence of the human species. To compete for survival, of course, the most resistant and adapted individuals to an environment with abundant challenges were the most prized to continue the hereditary lines of the clans.

Following this logic, traditional caring practices should not be understood as necessarily geared in evolution to the survival of all individuals. This would have produced overpopulation of the territorial ranges. In fact, traditional caring may have the character of presenting survival challenges to children, challenges that bring forth and separate the innate constitutional adaptation of certain children to overcome environmental hazards. Those failing the tests made way for those who overcame them, in the classical survival-to-reproduction of the fittest mandate of evolutionary biology.

To the extent that contemporary social ethics is based on the absolute respect for the right of all children to survive and thrive, any evolutionary imperative in caring practices must be replaced by the humanitarian imperative that, indeed, maximizes the survival of all individuals. The justification for the reform of traditional caring practices is precisely that of assuring the behaviors are geared expressly to protecting the health of all. Children with HIV may, in fact, ideally require caring practices that are different from those of the uninfected to eliminate even further the environmental risks that would threaten their health and imperil their survival.

Endemic poverty and resource constraints aside, the interaction of caretaker and care-practices arises in a context of more appropriate, and often novel practices to be introduced. With the decimation of the parental generation, young children often have to rely on older siblings or grandparents for their care. The latter may be the more entrenched adherents to the traditional child-care practices having more of an impact of selective - than assured - survival; it would likely prove more difficult to change the folkways of the grandparents. The older siblings have only minimal caring experience and would represent a blank slate upon which to imprint new attitudes and behavior. But the very lack of age and parenting experience rests confidence from the conduct of caring for younger siblings. So, with illness or absence of parents, the caring to promote good health of children is cast on the most insecure of footings in HIV endemic settings.

Child care also suffers from the excessive strain on human labor brought about by HIV/AIDS. Gillespie et al. [62] provide an analysis of the global cost of HIV/ AIDS. At a global level, HIV/AIDS was 28th in terms of causes of disability-adjusted life years (DALYs) in 1990, and is projected to be 10th in 2020. It is anticipated that HIV/AIDS will be the third leading cause of DALYs in 2020 in sub-Saharan Africa (an increase from seventh place in 1990), as well as in India (representing an enormous leap from low to high). The authors go on to explain that the full effect on labor is not adequately captured in these figures because the labor of healthy individuals diverted into other activities brought on by HIV/AIDS, such as caring practices for the infected and affected, is not included. White and Robinson [104] explain that the measured impact on household dependency ratios is inconclusive. This may be due to communities' or families' coping mechanisms that involve sending children to other homes through family or informal non-family networks, while employing prime-age labor to help them produce. The cost of these labor shifts may result in poorer child care as well as increased risk of HIV transmission. Child care in terms of basic education is also devastated as children are removed from school to help care for the sick, or to help families maintain a livelihood. The latter often translates into participating in risky behaviors, which eventually perpetuates the spread of HIV.

With the improbability of new external resources for care being brought to bare on already destitute communities, a 'positive deviance' (PD) approach to care has been raised [105-107] and explored. A PD inquiry identifies uncommon, model caretaker and/or household behaviors that result in positive child outcomes in a community [106]. These behaviors are known as positive deviant practices. It is assumed that programs that promulgate positive deviant practices are unlikely to run into research constraints. At the community level, PD 
programs should include planning, community orientation, situation analysis, PD inquiries, and community feedback within action planning [106]. One example comes from rural Pakistan, in which newborn care practices from exclusive breastfeeding to thermal protection and hygiene were identified as positive deviant practices and subsequently promoted [106]. Another comes from northern Vietnam, in which the quality of feeding assistance to toddlers was addressed [107]. The program found that affirmative, responsive child feeding, involving verbalization and appropriate encouragement to the children in their second year of life, was the positive behavior resulting in acceptance of food, and improved child nutrition and health status.

The specific and express merger of caring and caregiver competence to the HIV/AIDS epidemic are beginning to appear $[105,107,108]$. Lapping et al. [105] share early experience with the PD approach for the topic of this review (i.e. HIV/AIDS and food security). The consortium of authors suspect that their PD intervention accelerates change through catalyzing the processes of community mobilization, awareness raising, problemsolving, motivating for behavior change, advocacy, and actual adopting new behaviors. They admit, however, that they have yet to quantify any benefits for food security and health outcomes attributable to the PD approach [107]. A pair of experiences have been published from eastern Kenya, where the Lea Toto Kangemi Outreach Program provides support to families caring for HIVpositive children $[108,109]$; many of the children are orphans or will imminently be orphaned. In this inquiry, a lack of stigma was found to be a factor in greater care knowledge. Persons in the community who were younger, single and with less education experienced greater stigma [108]. The converse finding was a significant association between less expressed stigma and greater care knowledge [109]. The practical consequences of this would call for efforts to lower the stigma associated with HIV-infected households, and thus improve caring knowledge and practices for better child outcomes.

All of the accumulated factors of isolation due to low income, geography and stigma of HIV/AIDS weigh upon the resolution of child health. The aforementioned strategies for care support again rely on local planning and local development of resources. However, to the extent that the affected communities can make themselves visible, demanding that their rights to health be fulfilled by municipal, state, national and international authorities is a complementary approach. This is exemplified in the poor 'favelas' of Rio de Janeiro, Brazil, by the civil society organization, the Center for Health Promotion [110]. The community movement has created a sense of 'ownership' of social actions, targeting the determinants of local vulnerability, while raising an awareness of health rights.

\section{Conclusions and Projections}

If poverty were not so rampant as a background and fundamental characteristic to the HIV/AIDS epidemic, the challenges in nutrition and health would not be so formidable. For a world that has yet to eliminate severe poverty, the recipe would seem a huge hurdle to overcome, insofar as 'sustainable development requires political, economic, and social changes that include empowering the disenfranchised, widening access to assets and other resources, narrowing the gap between rich and poor, and adjusting consumption patterns so as to foster good stewardship of nature' [111].

Within the tall order prescription for sustainable development, HIV/AIDS represents an immense and growing challenge to the world's public health ingenuity, a drain on resources, and a cause of enormous suffering and stigmatization. Its era has been with us for a quarter of a century. The present analysis has shown the social origins of health care and nutritional problems. With its long latency period for the development of disease and the progression to death, our ability to understand and respond to its various health and social demands has been difficult.

The HIV/AIDS pandemic is only a quarter of a century old, and it is evolving and shifting in its epidemiological and pharmacological aspects. Here we have mobilized an immense body of literature demonstrating the pivotal role of diet, nutrition and food security in the efforts to mitigate the effects of the infection. The experience and arguments have shown us, however, the limits to developing 'evidence-based' interventions as the only approach to addressing the failures in child care and the gaping food insecurity breeches. The gaps in our knowledge have been identified, outlining priority needs for additional research to continue the mitigation. Table 6 lists some of the operational research questions identified by the expert panel in the WHO Consultancy [74]. The most severe assault of HIV/AIDS, however, occurs in the most resource-poor of settings, in which adequate address of the prevention, mitigation and care needs is still a luxury. Research resources compete directly with resources for interventions within a limit pool of available funds. 
Despite an effort to identify gaps in knowledge and priorities for new research, it was the conclusion of the WHO panel that much can and should be done to improve the health, nutrition and quality of life of PLHA [74]. Hence, as most of the workers at the program level $[43,96]$ and most of the academics who advise and inform policy $[62,89,92]$ have counseled, it is more important to assemble the experience and refine practices in the context of formulating immediate and ongoing actions to confront food security. Two of the major principles enunciated throughout this review are: (1) a comprehensive and holistic approach to the underlying problems which go beyond the specific individuals infected with HIV, and (2) basic work at the level of the communities with community consultation, involvement and sustainable responsibility.

With respect to the linkage between the care of children and child health, the HIV/AIDS epidemic presents many of the same challenges as those that impinge on food security. There is disruption of household stability, loss of income and accumulated resources, and emergence of caretakers who are too young and inexperienced or too elderly and debilitated to provide appropriate care. However, traditional care practices in societies will not always assure the survival of all children. For children with undernutrition and a compromised immune system, food- and water-borne pathogens from inadequate sanitary practices can be life-threatening. Moss et al. [112] recommend 'evidence-based, locally adapted guidelines for the care of children'; this again begs the question of how to partition resources between providing services versus investigating their provision.

In the absence of the luxury of funding for dedicated investigative research of the outstanding gaps in our fundamental and practical knowledge, at least the latter can be addressed in the context of hands-on experience on the ground. As shown in meetings such as the African Forum [96], a general notion of what works, what works well, and what does not work can be distilled by the collective experience of the field-worker community. Adaptation of interventions to the context of a setting and to changing realties on the ground is seen as a positive virtue. Emphasis is currently more on integrated HIV/AIDS and food and nutrition security programming and interventions that favor food security and child health.

The reality on the ground in the communities in which understaffed, under-equipped and under-resourced community workers and residents face the daily battle for food and care is, indeed, one of extremely strained coping
Table 6. Selected pertinent research questions to fill outstanding gaps in knowledge on food security-HIV/AIDS relationships

1 What are the effects of improved household food technology, dietary advice and provision of food given during community care on nutritional recovery, disease progression and quality of life?

2 What should food and nutrition support programs do differently because of HIV/AIDS? For example, should they change ration size or composition for the HIV-affected population? What are the criteria for targeting food to mitigate the effects of HIV/AIDS?

3 What are effective nutrition interventions for food security to mitigate the nutritional impact of HIV caused by reduced agricultural productivity and/or caring capacity?

4 What is the impact of antiretroviral therapy in malnourished populations? Does nutritional status affect the efficacy of therapy and the risk or severity of adverse events associated with it? Would nutrition interventions - particularly in undernourished populations and lactating mothers - provided concurrently with antiretroviral therapy result in better health outcomes?

Extracted from the WHO [70].

mechanisms on the verge of collapse. However, we must have a vision and projection that goes beyond the status quo. If we agree that food security is generally about a quantitative concept of having enough food to eat to avoid hunger and malnutrition, other aspects of a quality diet must emerge in both a short- and longer-term context for PLHA [113]. Food safety, in other words food free of contamination, is important in the immediate term as foodborne illness may be much more devastating for those with compromised immune defense. As discussed elsewhere in terms of overnutrition, moreover, the advent of accessible therapy for some seropositive populations raises the specter of long-term survival and issues of longterm health. A healthy diet, aimed at reducing non-communicable disease risks, needs to be considered as the final refinement beyond abundance and safety of food in line with the sage comments of Gopalan [47]: 'Household nutrition security means more than avoidance of chronic starvation. Policy makers of developing countries should set, as their target in the next century, the achievement of adequate nutrition rather than mere survival.' This is a more optimistic vision for all communities, embracing those living with HIV/AIDS. 


\section{References}

1 Gottlieb MS, Schanker HM, Fan PT, Weisman JT: Pneumocystis pneumonia - Los Angeles. MMWR 1981;30:1-3.

$>2$ Heeney JL, Dalgleish AG, Weiss RA: Origins of HIV and the evolution of resistance to AIDS. Science 2006;313:462-466.

$>3$ Piot P, Bartos M, Ghys PD, et al: The global impact of HIV/AIDS. Nature 2001;410:968973.

4 Shears P: Cholera. Ann Trop Med Parasitol 1994;88:109-122.

$\checkmark 5$ Guerrant RL, Carneiro-Filho BA, Dillingham RA: Cholera, diarrhea, and oral rehydration therapy: triumph and indictment. Clin Infect Dis 2003;37:398-405.

$\checkmark 6$ Henderson DA: Smallpox eradication. Public Health Rep 1980;95:422-426.

7 Zlotnik H: Demographic trends; in Caballero B, Popkin BM (eds): The Nutrition Transition: Diet and Disease in the Developing World. London, Academic Press, 2002, pp 71-107.

8 Rutengwe RM: Identifying strategic interventions for improving household food and nutrition security in an urban informal settlement, South Africa. Asia Pac J Clin Nutr 2004;13(suppl):S169.

$>9$ Walker N., Schwartländer J: Meeting international goals in child survival and HIV/ AIDS. Lancet 2002;360:284-289.

10 Hunter S, Williamson J: Children on the Brink 2000: Executive Summary - Updated Estimates and Recommendations for Intervention. The Synergy Project 2000. Washington, USAID, 2000, pp 1-32.

$>11$ Somerville MA, Orkin AJ: Human rights, discrimination and AIDS: concepts and issues. AIDS 1989;3(suppl 1):S283-S287.

12 Hecht R, Alban A, Taylor K, et al: Putting it together: AIDS and the millennium development goals. PLoS Med 2006;3:e455.

13 Haddad L: No longer off the menu: the welcome re-emergence of food on the nutrition agenda. Forum Nutr 2003;56:383-384.

14 The President's Emergency Plan for AIDS Relief. Report on Food and Nutrition for People Living with HIV/AIDS. Washington, Office of the US Global AIDS Coordinator, US Department of State, 2006

15 Scrimshaw NS, Taylor CE, Gordon JE: Interactions of nutrition and infection. Am J Med Sci 1959;237:367-403.

-16 Scrimshaw NS, Taylor CE, Gordon JE: Interactions of nutrition and infection. Monog Ser World Health Organ 1968;57:3-329.

$\checkmark 17$ Keusch GT, Farthing MJG: Nutrition and infection. Annu Rev Nutr 1986;6:131-154.

18 Scrimshaw NS, SanGiovanni JP: Synergism of nutrition, infection, and immunity: an overview. Am J Clin Nutr 1997;66:464S$477 \mathrm{~S}$.
19 Wanke CA, Silva M, Knox TA, et al: Weight loss and wasting remain common complications in individuals infected with human immunodeficiency virus in the era of highly active antiretroviral therapy. Clin Infect Dis 2000;31:803-805.

20 Ungar BLP, Ward DJ, Fayer R, Quinn CA: Cessation of cryptosporidium-associated diarrhea in an acquired immunodeficiency syndrome patient after treatment with hyperimmune bovine colostrum. Gastroenterology 1990;98:486-489.

21 Saini A, Nasser AS, Stewart CE: Waste management - cytokines, growth factors and cachexia. Cytokine Growth Factor Rev 2006; 7 475-486.

-22 MacDonald KS, Malonza I, Chen DK, et al: Vitamin A and risk of HIV-1 seroconversion among Kenyan men with genital ulcers. AIDS 2001;15:635-639.

23 Semba RD, Neville MC: Breast-feeding, mastitis, and HIV transmission: nutritional implications. Nutr Rev 1999;57:146-153.

24 Fawzi WW: Nutritional factors and vertical transmission of HIV-1: epidemiology and potential mechanisms. Ann NY Acad Sci 2000;918:99-114

25 Dreyfuss ML, Fawzi WW: Micronutrients and vertical transmission of HIV-1. Am J Clin Nutr 2002;75:959-970.

26 Downs JH, Cooper PA: HIV and lactation. Ann Nestlé [Engl] 2007;65:29-38

27 Tang AM, Graham NM, Kirby AJ, et al: Dietary micronutrient intake and risk progression to acquired immunodeficiency syndrome (AIDS) in human immunodeficiency virus type (HIV-1)-infected homosexual men. Am J Epidemiol 1993;138:937-951.

28 Tang AM, Graham NM, Saah AJ: Effects of micronutrient intake on survival in human immunodeficiency virus type I infection. Am J Epidemiol 1996;143:1244-1256.

29 Tang A, Graham N, Semba R, Saah A: Association between serum vitamin $A$ and $E$ levels and HIV-1 disease progression. AIDS 1997;11:613-620.

30 Baum MK, Shor-Posner G, Lu Y, et al: Micronutrients and HIV-1 disease progression. AIDS 1995;9:1051-1056.

31 Mehta S, Finkelstein JL, Fawzi W: Nutritional interventions in HIV-infected breastfeeding women. Ann Nestlé [Engl] 2007;65:3948.

32 Beck MA, Kolbeck PC, Shi Q, et al: Increased virulence of a human enterovirus (coxsackievirus B3) in selenium-deficient mice. J Infect Dis 1994;170:351-357.

33 Beck MA, Handy J, Levander OA: Host nutritional status: the neglected virulence factor. Trends Microbiol 2004;12:417-423.

34 Nelson HK, Shi Q, Van Dael P, et al: Host nutritional selenium status as a driving force for influenza virus mutations. FASEB J 2001; 15:1846-1848.
35 Beck MA, Nelson HK, Shi Q, et al: Selenium deficiency increases the pathology of in influenza virus infection. FASEB J 2001;15: 1481-1486.

36 Sazawal S, Black RE, Ramsan M, et al: Effects of routine prophylactic supplementation with iron and folic acid on admission to hospital and mortality in preschool children in a high malaria transmission setting: community-based, randomised, placebo-controlled trial. Lancet 2006;367:133-143.

37 Weinberg ED: Iron withholding: a defense against viral infections. Biometals 1996;9: 393-399.

38 Bobat R, Coovadia H, Stephen C, et al: Safety and efficacy of zinc supplementation for children with HIV-1 infection in South Africa: a randomised double-blind placebocontrolled trial. Lancet 2006;367:814-815.

39 Olsen A, Mwaniki D, Krarup H, Friis H: Low-dose iron supplementation does not increase HIV-1 load. J Acquir Immune Defic Syndr 2004;36:637-638.

40 Friis $\mathrm{H}$ (ed): Micronutrients and HIV Infection. Boca Raton, CRC Press, 2002.

41 Piot P: Keynote Address. Nutrition and HIV/ AIDS. Nutrition Policy Paper No. 20. SubCommittee on Nutrition. Geneva, SCN 2001, pp 7-10.

42 Whiteside A, Barnett T, George G, Van Niekerk AA: Through a glass, darkly: data and uncertainty in the AIDS debate. Developing World Bioeth 2003;3:49-76.

43 Tabi M, Vogel RL: Nutritional counselling: an intervention for HIV-positive patients. J Adv Nurs 2006;54:676-682.

44 Fields-Gardner C, Fergusson P; American Dietetic Association; Dietitians of Canada: Position of the American Dietetic Association and Dietitians of Canada: nutrition intervention in the care of persons with human immunodeficiency virus infection. J Am Diet Assoc 2004;104:1425-1441.

45 Tontisirin K, Bhattacharjee L: Food security and nutrition - a household perspective. Forum Nutr 2003;56:382-383.

46 Casey PH, Simpson PM, Gossett JM, et al: The association of child and household food insecurity with childhood overweight status. Pediatrics 2006;118:e1406-e1413.

47 Gopalan C: Achieving household nutrition security in societies in transition: an overview. Asia Pac J Clin Nutr 2001;10(suppl): S4-S12.

48 Kendall A, Olson CM, Frongillo EA Jr: Validation of the Radimer/Cornell measures of hunger and food insecurity. J Nutr 1995;125: 2793-2801.

49 Frongillo EA Jr, Rauschenbach BS, Olson $\mathrm{CM}$, et al: Questionnaire-based measures are valid for the identification of rural households with hunger and food insecurity. J Nutr 1997;127:699-705. 
-50 Onyango AW: Dietary diversity, child nutrition and health in contemporary African communities. Comp Biochem Physiol A Mol Integr Physiol 2003;136:61-69.

-51 Keenan DP, Olson C, Hersey JC, Parmer SM: Measures of food insecurity/security. J Nutr Educ 2001;33(suppl 1):S49-S58.

52 Rose D: Economic determinants and dietary consequences of food insecurity in the United States. J Nutr 1999;129(suppl):517S520 S.

53 Shariff ZM, Khor GL: Obesity and household food insecurity: evidence from a sample of rural households in Malaysia. Eur J Clin Nutr 2005;59:1049-1058.

54 Webb P, Coates J, Frongillo EA, et al: Measuring household food insecurity: why it's so important and yet so difficult to do. J Nutr 2006;136:1404S-1408S.

55 Nyindo M: Complementary factors contributing to the rapid spread of HIV-I in sub-Saharan Africa: a review. East Afr Med J 2005; 82:40-46.

56 Mhalu FS: Burden of diseases in poor resource countries: meeting the challenges of combating HIV/AIDS, tuberculosis and malaria. Tanzan Health Res Bull 2005;7:179184.

57 Chopra M, Darnton-Hill I: Responding to the crisis in sub-Saharan Africa: the role of nutrition. Public Health Nutr 2006;9:544550.

58 Watts J: Targets now set by G8 countries to reduce 'diseases of poverty'. Lancet 2000; 356:408.

59 Rukuni M: Africa: addressing growing threats to food security. J Nutr;132:3443S3448S.

60 Saasa OS: HIV/AIDS and Development Unsolved Challenges for Africa. Nutrition and HIV/AIDS. Nutrition Policy Paper No. 20. SubCommittee on Nutrition. Geneva, SCN, 2001, pp 19-27.

-61 Hunter SS, Bulirwa E, Kisseka E: AIDS and agricultural production. Report of a land utilization survey, Masaka and Rakai districts of Uganda. Land Use Policy 1993;10: 241-258.

62 Gillespie S, Haddad L, Jackson R: HIV/AIDS food and nutrition security: impacts and actions. 28th Session of the ACC/SCN Symposium on Nutrition and HIV/AIDS, Nairobi, 2001.

63 Cummings B, Mengistu M, Negash W, et al: Barriers to and facilitators for female participation in an HIV prevention project in rura Ethiopia: findings from a qualitative evaluation. Cult Health Sex 2006;8:251-266.

64 Hindin MJ: Women's input into household decisions and their nutritional status in three resource-constrained settings. Public Health Nutr 2006;9:485-493.

65 Kruger A, Lemke S, Phometsi M, et al: Poverty and household food security of black South African farm workers: the legacy of social inequalities. Public Health Nutr 2006; 9:830-836.
66 Thomas F: Stigma, fatigue and social breakdown: exploring the impacts of HIV/AIDS on patient and carer well-being in the Caprivi Region, Namibia. Soc Sci Med 2006;63: 3174-3187.

67 Thomas BE, Rehman F, Suryanarayanan D, et al: How stigmatizing is stigma in the life of people living with HIV: a study on HIV positive individuals from Chennai, South India AIDS Care 2005;17:795-801.

68 Mawar N, Saha S, Pandit A, Mahajan U: The third phase of HIV pandemic: social consequences of HIV/AIDS stigma and discrimination and future needs. Indian J Med Res 2005;122:471-484.

69 Reidpath DD, Brijnath B, Chan KY: An Asia Pacific six-country study on HIV-related discrimination: introduction. AIDS Care 2005;17(suppl 2):S117-S127.

70 VanLandingham MJ, Im-Em W, Saengtienchai C: Community reaction to persons with HIV/AIDS and their parents: an analysis of recent evidence from Thailand. J Health Soc Behav 2005;46:392-410.

71 Gillespie S, Haddad L, Jackson R: HIV/AIDS Food and Nutrition Security: Impacts and Actions. Nutrition and HIV/AIDS. Nutrition Policy Paper No. 20. SubCommittee on Nutrition. Geneva, SCN, 2001, pp 31-45.

72 Wyss K, Hutton G, N'Diekhor Y: Costs attributable to AIDS at household level in Chad. AIDS Care 2004;16:808-816.

73 Food and Nutrition Board, Institute of Medicine: Dietary Reference Intakes for Energy, Carbohydrate, Fiber, Fat, Fatty Acids, Cholesterol, Protein, and Amino Acids. Part 1, Summary and chapters 1-9. Washington National Academy Press, 2002.

74 World Health Organization: Nutrient Requirements for People Living with HIB/ AIDS. Report of Technical Consultation. Geneva, WHO, 2003.

75 Manuela de Paoli M, Manongi R, Klepp KI Are infant feeding options that are recommended for mothers with HIV acceptable, feasible, affordable, sustainable and safe? Pregnant women's perspectives. Public Health Nutr 2004;7:611-619.

76 Thior I, Lockman S, Smeaton LM, et al: Breastfeeding plus infant zidovudine prophylaxis for 6 months vs formula feeding plus infant zidovudine for 1 month to reduce mother-to-child HIV transmission in Botswana: a randomized trial: the Mashi Study. JAMA 2006;296:794-805.

77 Forrester JE, Tucker KL, Gorbach SL: Dietary intake and body mass index in HIVpositive and HIV-negative drug abusers of Hispanic ethnicity. Public Health Nutr 2004; 7:863-870

78 Paton NI, Sangeetha S, Earnest A, Bellamy R: The impact of malnutrition on survival and the CD4 cell response in HIV-infected patients starting antiretroviral therapy. HIV Med 2006;7:323-330.
79 Kim JH, Spiegelman D, Rimm E, Gorbach SL: The correlates of dietary intake along HIV-positive adults. Am J Clin Nutr 2001;74: 852-861.

80 Betsi NA, Koudou BG, Cisse G, et al: Effect of an armed conflict on human resources and health systems in Cote d'Ivoire: prevention of and care for people with HIV/AIDS. AIDS Care 2006;18:356-365

81 Spiegel PB: HIV/AIDS among conflict-affected and displaced populations: dispelling myths and taking action. Disasters 2004;28: 322-339.

82 Vorster HH, Venter CS, Wissing MP, Margetts BM: The nutrition and health transition in the North West Province of South Africa: a review of the THUSA (Transition and Health during Urbanisation of South Africans) study. Public Health Nutr 2005;8:480490 .

83 Bourne LT, Lambert EV, Steyn K: Where does the black population of South Africa stand on the nutrition transition? Public Health Nutr 2002;5:157-162.

84 Zimmet P: Epidemiology of diabetes mellitus and associated cardiovascular risk factors: focus on human immunodeficiency virus and psychiatric disorders. Am J Med 2005;118(suppl 2):3S-8S

85 Amorosa V, Synnestvedt M, Gross R, et al: A tale of 2 epidemics: the intersection between obesity and HIV infection in Philadelphia. J Acquir Immune Defic Syndr 2005;39:557561.

86 Jaime PC, Florindo AA, Latorre MD, Segurado AA: Central obesity and dietary intake in HIV/AIDS patients. Rev Saude Publica 2006;40:634-640

87 Rosegrant MW, Cline SA: Global food security: challenges and policies. Science 2003; 302:1917-1919.

88 Gregory PJ, Ingram JS, Brklacich M: Climate change and food security. Philos Trans R Soc Lond B Biol Sci 2005;360:2139-2148.

89 Gillespie S: AIDS, Poverty and Hunger: Challenges and Response. Food Policy Statement. Washington, International Food Policy Research Institute, 2006.

90 Gillespie S: Interventions and impacts: how HIV/AIDS interacts with food and nutrition security: an overview to volume 1 . Int Conf HIV/AIDS and Food and Nutrition Security, Durban, 2005

91 Gillespie S: Policy and program response: responding to the Interactions between HIV/ AIDS an food and nutrition security: an overview to volume 2. Int Conf HIV/AIDS and Food and Nutrition Security, Durban, 2005.

92 Parley PG, Alston M, Piggett RR: Agricultural R\&D in the Developing World, Too Little Too Late? Washington, International Food Policy Research Institute, 2006.

$>93$ Kadiyala S, Gillespie S: Rethinking food aid to fight AIDS. Food Nutr Bull 2004;25:271282 . 
94 World Food Programme: Food Security, Food Aid and HIV/AIDS: Project Ideas to Address the HIV/AIDS Crisis. Rome, WFP, 2001.

$\$ 95$ Marchione TJ: Interactions with the recipient community in targeted food and nutrition programs. J Nutr 2005;135:886-889.

96 The African Forum 2006: An Integrated Response to the Dual Epidemic of HIV/ AIDS and Food Insecurity, Lukasa, Zambia, 2006.

97 Martin-Prevel Y: 'Care' and public nutrition. Sante 2002;12:86-93.

98 Engle PL, Bentley M, Pelto G: The role of care in nutrition programmes: current research and a research agenda. Proc Nutr Soc 2000;59:25-35.

$\$ 99$ Ghosh S, Shah D: Nutritional problems in urban slum children. Indian Pediatr 2004; 41:682-696.

100 Shetty AK, Powell G: Children orphaned by AIDS: a global perspective. Semin Pediatr Infect Dis 2003;14:25-31.

101 Oleke C, Blystad A, Rekdal OB: 'When the obvious brother is not there': political and cultural contexts of the orphan challenge in northern Uganda. Soc Sci Med 2005;61: 2628-2638.
102 Nyambedha EO, Wandibba S, AagaardHansen J: Policy implications of the inadequate support systems for orphans in western Kenya. Health Policy 2001;58:83-96.

103 Engle PL, Pelto G, Bentley P: Care for nutrition and development. J Indian Med Assoc 2000;98:530-535.

104 White J, Robinson E: HIV/AIDS and Rural Livelihoods in Sub-Saharan Africa. Policy Series 6. Chatham, Natural Resources Institute, 2000.

105 Lapping K, Marsh DR, Rosenbaum J, et al: The positive deviance approach: challenges and opportunities for the future. Food Nutr Bull 2002;23(suppl):130-137.

106 Marsh DR, Sternin M, Khadduri R, et al: Identification of model newborn care practices through a positive deviance inquiry to guide behavior-change interventions in Haripur, Pakistan. Food Nutr Bull 2002; 23(suppl):109-118.

107 Ha PB, Bentley ME, Pachon H, et al: Caregiver styles of feeding and child acceptance of food in rural Viet Nam. Food Nutr Bull 2002;23(suppl):95-100.
108 Hamra M, Ross MW, Orrs M, D’Agostino A: Relationship between expressed HIV/ AIDS-related stigma and HIV-beliefs/ knowledge and behaviour in families of HIV infected children in Kenya. Trop Med Int Health 2006;11:513-527.

109 Hamra M, Ross MW, Karuri K, et al: The relationship between expressed HIV/AIDSrelated stigma and beliefs and knowledge about care and support of people living with AIDS in families caring for HIV-infected children in Kenya. AIDS Care 2005; 17:911-922.

110 Edmundo K, Guimaraes W, Vasconcelos Mdo S, et al: Network of communities in the fight against AIDS: local actions to address health inequities and promote health in Rio de Janeiro, Brazil. Promot Educ 2005; suppl 3:15-19.

111 Struble MB, Aomari LL: Position of the American Dietetic Association: addressing world hunger, malnutrition, and food insecurity. J Am Diet Assoc 2003;103:10461057.

112 Moss WJ, Ramakrishnan M, Storms D, et al: Child health in complex emergencies. Bull World Health Organ 2006;84:58-64.

113 Lobstein T: Food policies: a threat to health? Proc Nutr Soc 2002;61:579-585. 